\title{
Listening: The Forgotten Communication Skill
}

\section{Christa L Arnold*}

Associate Professor, University of North Florida, USA

Everyone believes they are a good listener. No one wants to be considered a "bad" listener. People "assume" they automatically can listen if they simply can hear. This is not so, hearing is a physiological act, while listening involves hearing the stimuli, attending to stimuli and trying to make sense of stimuli. Yet we are not as generous about other's listening abilities as we are about ourselves. Listening surveys often find that we rate ourselves as good to excellent listeners but fair to poor listeners for other people. Very rarely do people actually study, take a course, workshop, or seminar in listening training. Further, many people do not even know there are types of listening other than "active" or "passive" listening. Is there really such a thing as "passive listening?" I would basically define passive listening as "sleeping." I have taught an undergraduate listening course and many listening training workshops for professionals and medical students for over twenty years, and never has anyone entered the listening course or workshop/seminar thinking they needed listening skill building. I usually convince them otherwise by doing some simple opening exercises involving memory and listening. Then I move on to discussing the types of listening, discussed in detail by Andrew Wolvin and Carolyn Coakley in their book Listening,such as discriminative (listening beyond the content and into emotion); comprehensive (listening to understand, remember and retain, especially during interruptions); therapeutic (diagnostic listening by qualified medical personnel); critical (listening to comprehend and evaluate); empathic (trying to understand the others point of view); and appreciative (listening for cognitive stimulation and enjoyment); plus the many skills involved for each type of listening. Usually an hour into the listening workshop or course, everyone is now "all ears" or officially listening. Another assessment for my students and professionals is the Larry Barker and KittieWatson Listener Preference Profile which provides a way to learn about the listening preferences of yourself as well as others. They suggest that four listening preferences be distinguished:
- people-oriented listeners (concerned with how listening influences relationships with others);

- action-oriented listeners (concentrate intensely on the task at hand);

- content-oriented listeners (carefully evaluate everything they hear; and

- time-oriented listeners (value time management and efficiency while listening).

People having different listening preferences, or a combination of preferences, would impact the type of training and listening skill building each person may need.The point to this profile is that we all listen differently. There are not only gender differences in listening but the way we cognitively process and listen differs from person to person. Frequently academic and medical professionals, the general public, and students believe that taking listening training courses are "common sense" and feel they already have sufficient communication and listening skills without the need for further training. Often listening is solely referred to as "empathy" in many discussions. Yet before empathy can occur, before listening can even occur, individuals must recognize that someone needs listening by spotting verbal and/or nonverbal cues given by the speaker. Listening at the start of the interaction is integral to models of conversation such as gathering data on the person and defining the person's story. Nonverbal communication is essential to the art of listening. Reading body language, facial expression, tone, inflection, paralanguage, and deception-leakage cues are necessary to fully understand and listen to the person speaking. Arguably basic listening styles, types, and verbal/nonverbal skills should be addressed in any professional curriculum, including secondary and even elementary education. Alas, rarely is listening ever really taught as a skills based course or unit. We kind of lump it into the term "communicating" and forget about the power of good listening. As I end my rant on the importance of listening, I refer to a quote from Frank Tyger that rings true with me and I bet with you too:"Be a Good Listener: Your Ears Will Never Get You In Trouble.”
*Corresponding author: Christa L Arnold, Associate Professor, University of North Florida, USA, Tel:904-620-3804; E-mail: christa.arnold@unf.edu

Received September 29, 2014; Accepted September 29, 2014; Published October 05, 2014

Citation: Arnold CL (2014) Listening: The Forgotten Communication Skill. J Mass Communicat Journalism 4: e155. doi:10.4172/2165-7912.1000e155

Copyright: (c) 2014 Arnold CL. This is an open-access article distributed under the terms of the Creative Commons Attribution License, which permits unrestricted use, distribution, and reproduction in any medium, provided the original author and source are credited. 